\title{
GLYX-13 Produces Rapid Antidepressant Responses with Key Synaptic and Behavioral Effects Distinct from Ketamine
}

\author{
Rong-Jian Liu', ${ }^{1,5}$ Catharine Duman',5, Taro Kato',2, Brendan Hare', Dora Lopresto', Eunyoung Bang', \\ Jeffery Burgdorf', Joseph Moskal ${ }^{3,4}$, Jane Taylor', George Aghajanian' and Ronald S Duman', \\ 'Departments of Psychiatry and Neurosciences, Yale University School of Medicine, New Haven, CT, USA; ${ }^{2}$ Sumitomo Dainippon Pharma Co, Suita, \\ Osaka, Japan; ${ }^{3}$ Falk Center for Molecular Therapeutics, Department of Biomedical Engineering, Northwestern University, Evanston IL, USA; \\ ${ }^{4}$ Naurex, Inc., Evanston, IL, USA
}

\begin{abstract}
GLYX-I 3 is a putative NMDA receptor modulator with glycine-site partial agonist properties that produces rapid antidepressant effects, but without the psychotomimetic side effects of ketamine. Studies were conducted to examine the molecular, cellular, and behavioral actions of GLYX-I 3 to further characterize the mechanisms underlying the antidepressant actions of this agent. The results demonstrate that a single dose of GLYX-I 3 rapidly activates the mTORCI pathway in the prefrontal cortex (PFC), and that infusion of the selective mTORCI inhibitor rapamycin into the medial PFC (mPFC) blocks the antidepressant behavioral actions of GLYX-I3, indicating a requirement for $\mathrm{mTORCI}$ similar to ketamine. The results also demonstrate that GLYX- 13 rapidly increases the number and function of spine synapses in the apical dendritic tuft of layer $\vee$ pyramidal neurons in the mPFC. Notably, GLYX-I 3 significantly increased the synaptic responses to hypocretin, a measure of thalamocortical synapses, compared with its effects on 5-HT responses, a measure of corticalcortical responses mediated by the 5- $\mathrm{HT}_{2 \mathrm{~A}}$ receptor. Behavioral studies further demonstrate that GLYX-I3 does not influence 5-HT 2 receptor induced head twitch response or impulsivity in a serial reaction time task (SRTT), whereas ketamine increased responses in both tests. In contrast, both GLYX-I3 and ketamine increased attention in the SRTT task, which is linked to hypocretin-thalamocortical responses. The differences in the $5-\mathrm{HT}_{2}$ receptor synaptic and behavioral responses may be related to the lack of psychotomimetic side effects of GLYX-I 3 compared with ketamine, whereas regulation of the hypocretin responses may contribute to the therapeutic benefits of both rapid acting antidepressants.
\end{abstract}

Neuropsychopharmacology (2017) 42, I231-1242; doi:I0.1038/npp.2016.202; published online 19 October 2016

\section{INTRODUCTION}

The current needs for improved antidepressant treatments are underscored by the high incidence of major depressive disorder (MDD) which affects millions of people worldwide, as well as the inability of currently used drugs to adequately treat a significant portion of MDD sufferers (Trivedi et al, 2006). In addition, the significant time-lag of several weeks to months before therapeutic effectiveness is achieved with currently used drugs further emphasizes the need for novel agents. In contrast, rapid antidepressant actions, within hours have been shown for the $N$-methyl-D-aspartate (NMDA) receptor antagonist ketamine, notably in treatment resistant patients (Abdallah et al, 2015; Berman et al, 2000). These clinical findings are supported by basic research studies demonstrating similar rapid antidepressant actions in animal models (Li et al, 2010; Maeng et al, 2008). In addition,

\footnotetext{
*Correspondence: Dr RS Duman, Departments of Psychiatry and Neurosciences, Yale University School of Medicine, 34 Park Street, New Haven, CT 065 I9, USA, Tel: + I 203974 7723, Fax: + I 203974 7724, E-mail: ronald.duman@yale.edu

${ }^{5}$ Co-first authors.

Received 25 May 2016; revised 18 August 2016; accepted 29 August 2016; accepted article preview online 16 September 2016
}

the antidepressant effects of ketamine are sustained for 1-2 weeks in depressed patients and in animal models, indicating long-lasting synaptic alterations that outlast the acute drug exposure (Duman and Aghajanian, 2012).

GLYX-13 is a novel glutamatergic compound that also produces rapid antidepressant actions (Burgdorf et al, 2013; Moskal et al, 2016). Similar to ketamine, preliminary studies demonstrate that GLYX-13 produces improvements in depression symptoms in human patients within hours of a single dose (Burch et al, 2016). The antidepressant actions of GLYX-13 in animal models can last up to 2 weeks following a single dose, suggesting that adaptive neuroplasticity to the initial drug actions underlies the sustained behavioral responses. Thus, GLYX-13 and ketamine have similarities in that both agents act through glutamatergic mechanisms and both exert rapid effects that are sustained beyond the time of acute drug exposure.

A significant limitation for widespread use of ketamine is the occurrence of acute, transient psychotomimetic and dissociative side effects, as well as abuse potential (Abdallah et al, 2015). In contrast, the putative antidepressant effects of GLYX-13 occur in the absence of psychotomimetic features, dissociative side effects or evidence for abuse potential (Burgdorf et al, 2013; Moskal et al, 2016). Although ketamine 
and GLYX-13 both have primary glutamatergic actions, understanding the mechanistic differences between these two drugs could provide insights into dissociating the rapid antidepressant $v s$ psychotomimetic consequences of modulating glutamate transmission.

Ketamine is an NMDA receptor open-channel blocker, and the rapid antidepressant actions of ketamine have been linked to a paradoxical burst of glutamate in the medial prefrontal cortex (mPFC; Moghaddam et al, 1997). GLYX-13 also acts at the NDMA receptor but functions as a partial agonist at the glycine site of the receptor (Moskal et al, 2005, Moskal et al, 2016). It is currently unknown whether the effects of GLYX-13 are associated with changes in extracellular glutamate. However, the antidepressant actions of both GLYX-13 and ketamine are blocked by pretreatment with an AMPA receptor antagonist, indicating a requirement for glutamate-AMPA receptor activity (Burgdorf et al, 2013; Li et al, 2010; Maeng et al, 2008).

We have previously demonstrated that ketamine increases synaptic number and function in the $\mathrm{MPFC}$, and shown that these effects depend on mTORC1 signaling (Li et al, 2010; Li et al, 2011). GLYX-13 is reported to enhance neuroplasticity suggesting that it may also enhance synaptic function (Burgdorf et al, 2015a, 2015b). In the current study, we compared the influence of GLYX-13 and ketamine on the mTORC1-signaling pathway and on the number and function of spine synapses in the rat mPFC. The results demonstrate overlap in the actions of these two rapid acting agents on mTORC1 signaling, but also indicate differences in synaptic responses that could underlie the antidepressant $v s$ psychotomimetic behavioral differences.

\section{MATERIALS AND METHODS}

\begin{abstract}
Animals
Male Sprague Dawley rats (Charles River Laboratories) and male C57Bl/6 mice (Jackson Laboratories) 8-12 weeks of age were group housed on a 12-h light-dark cycle with lights on at 0700 hours. Food and water were available ad libitum. Animals were randomly assigned to treatment groups for all experiments, and for the SSRT were allocated into balanced treatment groups based on response levels following training. All procedures were in accordance with the NIH guidelines for the care and use of laboratory animals and the Yale University Institutional Animal Care and Use Committee.
\end{abstract}

\section{Drugs and Surgery}

GLYX-13 (gift from Naurex, Evanston, IL) was administered by tail vein injection to reduce degradation of the tetrapeptide. (R,S)-Ketamine hydrochloride (Sigma-Aldrich St. Louis, $\mathrm{MO})$ was administered as a single injection $(10 \mathrm{mg} / \mathrm{kg}$, i.p. or i.v. as indicated). For intracerebral infusion, rats were anesthetized and implanted with bilateral guide cannulae into the mPFC as previously described (Li et al, 2010). After 13-14 days of recovery, rats were bilaterally infused with a rapamycin (Cell Signaling; $0.005 \mathrm{nmol}$ per side) or $10 \%$ DMSO (vehicle).

\section{Antidepressant Behavioral Models}

The forced-swim test (FST) and novelty-suppressed feeding test (NSFT) were conducted in rats as previously described (Li et al, 2010), $24 \mathrm{~h}$ after vehicle or GLYX-13 administration. The female urine-sniffing test (FUST) was conducted in male rats according to the published procedures (Malkesman et al, 2010), and consisted of habituation (60 min) to the presence of a cotton-tipped applicator in the home cage, then the applicator dipped in tap water for $5 \mathrm{~min}$, followed $45 \mathrm{~min}$ later with a $5 \mathrm{~min}$ exposure to an applicator infused with fresh urine collected from 11- to 14-week-old females. Behavior was video recorded and total time spent sniffing the cotton-tipped applicator was recorded by an investigator blinded to treatment. Locomotor activity was determined as previously described (Digiscan animal activity monitor; Omnitech Electronics, Columbus, Ohio; Warner-Schmidt and Duman, 2007).

\section{DOI-Induced Head Twitch}

Head twitch responses were assessed according to published methods (Halberstadt and Geyer, 2013). C57Bl/6 mice were habituated to testing chambers for $30 \mathrm{~min}$ and $24 \mathrm{~h}$ later they received acute doses of either ketamine $(10 \mathrm{mg} / \mathrm{kg}$, i.v.) or GLYX-13 (3 mg/kg, i.v.). Twenty-four hour later mice received 1-(2,5-dimethoxy-4-iodophenyl)-2-aminopropane (DOI) at a dose of $5 \mathrm{mg} / \mathrm{kg}$, i.p. and the head twitch response was scored over $30 \mathrm{~min}$.

\section{Three Choice Serial Reaction Time Task}

For Serial Reaction Time Task (SRTT) training, animals are trained to attend to a series of nose-poke ports awaiting a stimulus presentation in one of the ports. The inter-trial interval (ITI) and duration of stimulus presentation can then be modified to challenge the animal's ability to withhold responses over longer ITI's as a test of impulsivity, or respond correctly at increasingly shorter stimulus durations as a test of attention. $\mathrm{C} 57 \mathrm{Bl} / 6$ mice were trained to respond to an illuminated nose-poke port as described previously (Scott and Taylor, 2014) until a 70\% correct criterion was met on trials with a $5 \mathrm{~s}$ stimulus interval and $5 \mathrm{~s}$ ITI. Performance was assessed through analysis of the percent correct responses (correct/total trials), percent accurate responses (correct/correct+incorrect), percent omissions (no response/total trials), and percent premature (ITI response/total trials). Twenty-four hours after reaching criterion, groups were balanced, administered ketamine or saline, and tested over the next 3 days. The first test assessed attention by presenting trials with $5,2,1$ or $0.5 \mathrm{~s}$ stimulus durations ( $5 \mathrm{~s}$ ITI) in a pseudorandom manner. The second test assessed impulsivity by presenting trials with 2 , 5,7 or $10 \mathrm{~s}$ ITIs ( $5 \mathrm{~s}$ stimulus duration) in a pseudorandom manner. The final challenge test presented a pair of trials at the shortest stimulus duration or longest ITI as in the previous tests. Following a 14-day period with no testing animals were given five training sessions to re-establish baseline performance. Twenty-four hours later animals were counterbalanced based on performance and prior drug treatment and administered GLYX-13 or saline. Drug 
administration was followed $24 \mathrm{~h}$ later by the challenge test, as described above.

\section{Western Blotting}

Western blot analysis of mTORC1 and synaptic proteins were conducted on crude synaptoneurosome preparations of rat prefrontal cortex, hippocampus, or striatum as previously described (Li et al, 2010). Primary antibodies included phospho-mTOR (Ser2448), total mTOR, phospho-p70S6K (Thr389), total p70S6K, phospho-4EBP1 (Thr37/46), phospho-ERK (Thr202/Tyr204), total ERK, Phospho-AKT (Ser473), total AKT, PSD95, GluR1, Synapsin1, GAPDH, (Cell Signaling, $1: 1000$ ) and c-fos (Santa Cruz, 1:500). After secondary antibody incubation bands were detected using enhanced chemiluminescence (ECL). Densitometric analysis of phospho- and total immunoreactivity for each protein was conducted using Image Lab (Bio-Rad). Immunoreactivity was normalized to saline-treated control group values for each protein.

\section{Immunohistochemistry}

c-Fos immunohistrochemistry was conducted as previously described (Fuchikami et al, 2015). Rat brain slices were incubated with primary antibody (rabbit anti-c-Fos 1:500; Santa Cruz Biotechnology) and then secondary antibody (1:500 biotinylated goat anti-rabbit, Vector Laboratories). The numbers of c-Fos-positive cells were counted from four coronal sections per animal.

\section{Electrophysiology}

Brain slices were prepared as previously described (Liu et al, 2015; Liu and Aghajanian, 2008). Pyramidal neurons in layer $\mathrm{V}$ of coronal slices of mPFC $(400 \mu \mathrm{m})$ were visualized by videomicroscopy and whole-cell recordings were performed with an Axoclamp-2B amplifier (Axon Instruments). Neurobiotin $(0.3 \%)$ was added to the pipette solution to mark cells for later imaging. Postsynaptic currents were studied in the continuous single-electrode voltage-clamp mode $(3000 \mathrm{~Hz}$ low-pass filter) clamped near resting potential $(75 \pm 5 \mathrm{mV})$. After completion of recording, slices were transferred to $4 \%$ paraformaldehyde $(0.1 \mathrm{M}$ phosphate buffer) and stored overnight at $4^{\circ} \mathrm{C}$. Slices were then processed with streptavidin conjugated to Alexa 594 $(1: 1000)$ for visualization of labeled cells.

\section{Spine Analysis}

Labeled mPFC layer V neurons were imaged by two-photon laser scanning and spine density was determined as previously described (Li et al, 2010; Liu et al, 2015). Dendrites were sampled at tips of tuft branches, at proximal tuft dendrites just distal to the bifurcation and midway between distal and proximal sites (average dendritic segment, 40-50 $\mu \mathrm{m})$. Spine density and spine head diameter were analyzed by Neurolucida software 10.2 (Autoneuron/Autospine; MicroBrightField, Williston, VT). Images were also collected on an Olympus confocal laser scanning microscope equipped with a $\times 100,1.42 \mathrm{NA}$ objective at a zoom of $\times 5$ (voxel size $0.049 \mu \mathrm{m} \times 0.049 \mu \mathrm{m} \times 0.01 \mu \mathrm{m}$ ). Computerized analysis of z-stack images was performed in deconvolved confocal image stacks (AutoquantX Version 3.0.1, Media Cybernetics, Bethesda, MD) and spines were and quantified by an experimenter blinded to treatments, using NeuronStudio software (Rodriguez et al, 2008).

\section{Statistics}

Data for signaling proteins were analyzed using one-way ANOVA. Effects were considered significant if $p<0.05$ and differences between individual group means were then assessed by post hoc Student's $t$-tests or Fischer's LSD as indicated. Data from behavioral tests for antidepressant-like activity and locomotor activity were analyzed using the Kruskal-Wallis test. Treatment groups were compared to the veh/veh control group with post hoc Dunn's test. In cases where group sizes were unequal or were small ( $n=4$ or 5$)$, effect sizes were also calculated, and are reported as Cohen's $d /$ Hedge's $g$ values for standard mean difference. Treatment effects in the SRTT were assessed using a repeated measures two-way ANOVA (treatment $\times$ trial type) and post hoc pairwise comparisons were made for ketamine and GLYX-13 treatments relative to their respective control groups using Student's $t$-tests with Bonferroni's correction. Results are presented as mean \pm SEM. Analysis was conducted using SPSS or GraphPad Prism 6 software.

\section{RESULTS}

\section{GLYX-13 Increases mTORC1 Signaling in the PFC}

Previous studies demonstrate that ketamine increases the phosphorylation of mTORC1 signaling proteins and studies were conducted to determine if GLYX-13 produces similar effects (Li et al, 2010, 2011; Liu et al, 2013). GLYX-13 was administered by tail vein injection to reduce degradation of the tetrapeptide; for comparison ketamine was also administered by tail vein injection. A single dose of GLYX-13 (3 mg/ $\mathrm{kg}$, i.v.), which produces antidepressant behavioral responses (Burgdorf et al, 2013), rapidly increased levels of phosphomTOR, phospho-p70S6K1, phospho-4EBP1, phospho-ERK and phospho-Akt in mPFC (Figure 1a-e). A single dose of ketamine $(10 \mathrm{mg} / \mathrm{kg}$, i.v.) produced similar effects on phospho-p70S6K and phospho-4EB-P1 although there was no significant effect on phospho-mTOR, phospho-Akt, or phospho-ERK in the first cohort tested $(n=4)$. In a subsequent cohort $(n=5)$ ketamine was administered i.p. $(10 \mathrm{mg} / \mathrm{kg})$ and did increase levels of phospho-mTOR, as well as the other signaling proteins tested with a magnitude similar to GLYX-13 (Figure 1a-e) as previously reported (Li et al, 2010, 2011; Liu et al, 2013). This could be due to pharmacokinetic differences since i.v. dosing would result in a more rapid increase in brain levels of ketamine and stimulation of mTORC1 signaling; since ketaminestimulation of mTORC1 signaling is transient and returns to basal levels by $2 \mathrm{hr}$ after i.p. dosing (Li et al, 2010) the transient stimulation and return to basal levels after i.v. dosing would be faster and could account for the reduced effects observed at the $1 \mathrm{~h}$ time point. Similar effects were observed in hippocampus in response to GLYX-13 or ketamine (i.v. and/or i.p. dosing), although there was no effect on phospho-Akt (Supplementary Figure 1). There were 

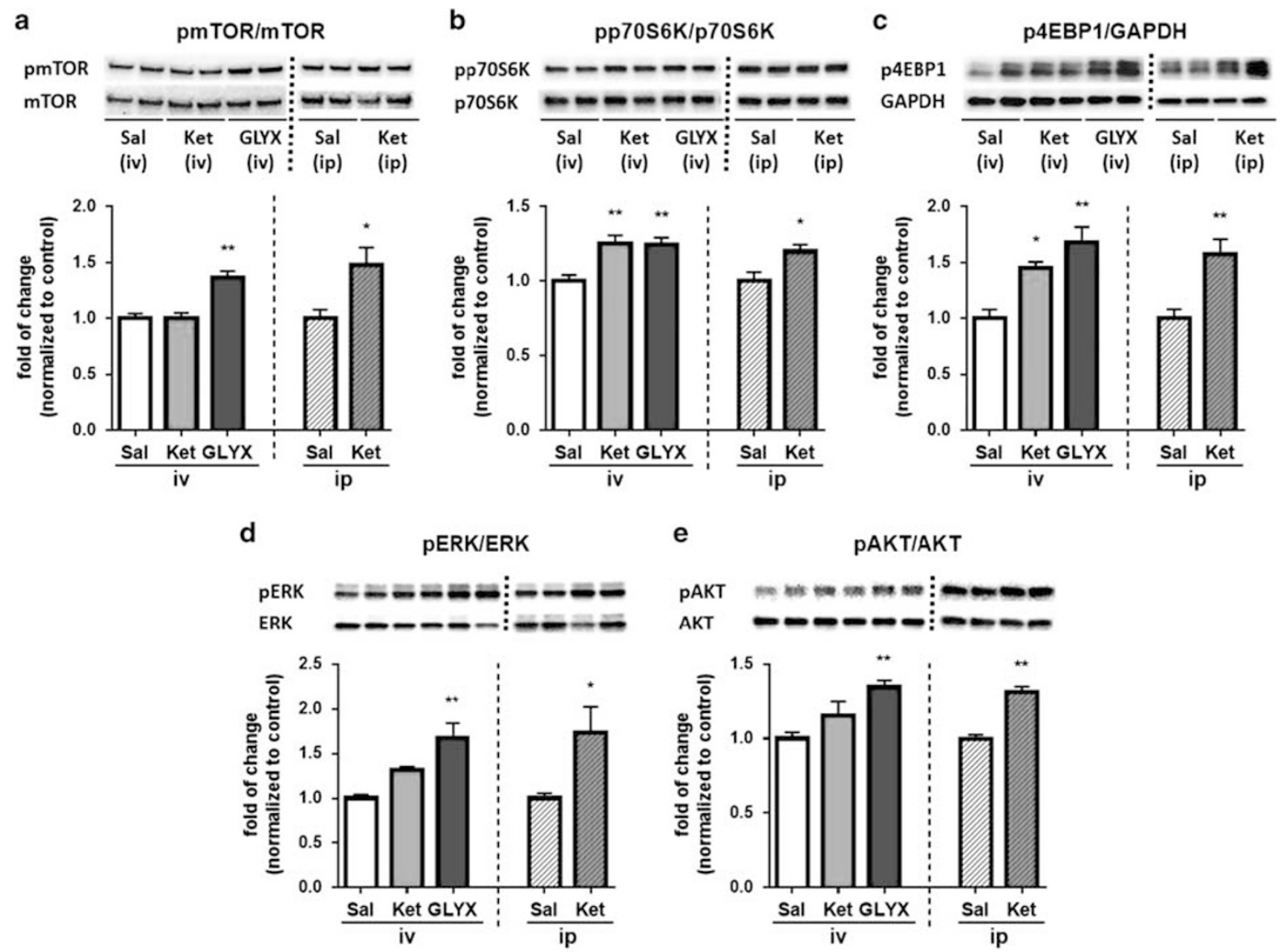

Figure I GLYX-13 increases levels of $\mathrm{mTORCl}$ signaling proteins in PFC. (a) Rats were administered vehicle (i.v.), GLYX-I3 (3 mg/kg, i.v.) or ketamine ( $10 \mathrm{mg} / \mathrm{kg}$, i.v.) and PFC dissections were collected I h later. Additional groups of rats received vehicle and ketamine by i.p. administration ( $10 \mathrm{mg} / \mathrm{kg}$; right side of each bar graph). Levels of the phosphorylated forms of (a) mTOR, (b) p70S6K, (c) 4EBPI, (d) ERK, and (e) Akt in crude synaptosomal preparations were determined by western blot analysis; levels of total protein were also determined to control for loading differences. Representative images of immunolabeled bands are shown for each phospho- and total protein. Protein bands were analyzed using enhanced chemiluminescence and phosphoproteins were normalized to their respective total protein levels. The results are shown as mean \pm SEM $n=9$ (sal), 4 (ket), 9 (GLYX-I3) for i.v. administration. One-way ANOVA (a) $F_{2,19}=15.40, p<0.000 I$. (b) $F_{2,19}=10.14, p<0.0010$. (c) $F_{2,19}=1 \mathrm{I} .1 \mathrm{I}, p<0.0006$. (d) $F_{2,19}=9.23, p<0.00 I 6$. (e) $F_{2.19}=12.58, p<0.0003$. $* p<0.05$ and $* * p<0.0$ I compared with vehicle control, Fischer's post hoc test. For i.p. administration $n=5$ per group, $* p<0.05$ and ${ }^{*} *$ * $p<0.01$, Student's t-test.

no significant effects on mTORC1 signaling in the dorsal striatum in response to either GLYX-13 or ketamine (Supplementary Figure 1).

To determine whether the antidepressant-like behavioral actions of GLYX-13, like ketamine (Li et al, 2010, 2011), require $\mathrm{mTORC1}$ signaling, the selective $\mathrm{mTORC1}$ inhibitor rapamycin was infused into the $\mathrm{mPFC} 30 \mathrm{~min}$ before GLYX-13 (3 mg/kg, i.v.); $24 \mathrm{~h}$ later behavior was tested (Figure 2a). GLYX-13 produced a robust antidepressant response in the FST (Figure 2c) and NSFT (Figure 2e); there was no effect on home cage feeding or locomotor activity (Figure $2 \mathrm{f}$ and $\mathrm{g}$ ). We also found that a single dose of GLYX-13 significantly increased time sniffing female urine, but not water in the FUST (Figure 2d), a validated test of rodent reward-seeking behavior and a relevant mood disorder model (Malkesman et al, 2010). Rapamycin infusion into mPFC prior to GLYX-13 administration completely blocked the behavioral actions of GLYX-13 in these three antidepressant models (Figure 2c-e). Rapamycin infusion prior to vehicle was tested in the first cohort of animals $(n=4)$ and had no effect on behavior, as previously reported (Li et al, 2010, 2011).

\section{GLYX-13 Increases c-Fos Immunolabelling in mPFC}

Previous studies demonstrate that ketamine causes a rapid, transient burst of glutamate in the mPFC (Moghaddam et al, 1997) that is thought to underlie the subsequent synaptic and behavioral actions of ketamine (Duman et al, 2016). The behavioral effects of both ketamine and GLYX-13 are blocked by pretreatment with an AMPA receptor antagonist, indicating a requirement for glutamate-AMPA activity (Burgdorf et al, 2013; Maeng et al, 2008; Li et al., 2010). Ketamine rapidly increases c-Fos, a marker of neuronal activity, in the mPFC, consistent with stimulation of glutamate-AMPA signaling (Fuchikami et al, 2015). Immunoblot analysis shows that GLYX-13 also increases c-Fos immunoreactivity in the PFC (Supplementary Figure 2a). Immunohistochemistry demonstrates that GLYX-13 increases c-Fos labeling in the infralimbic mPFC (Supplementary Figure 2b), with no 


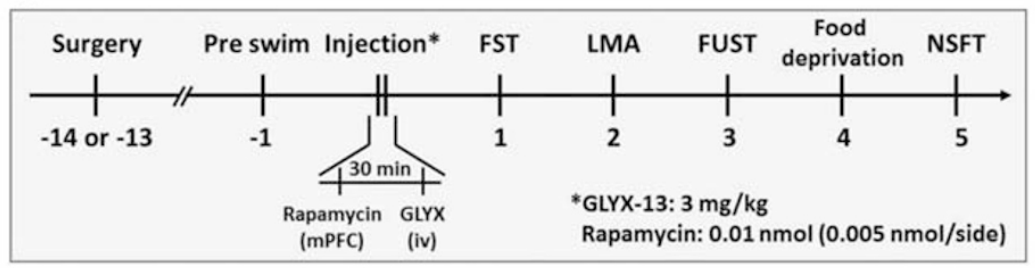

b

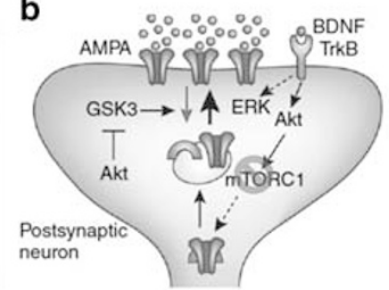

C

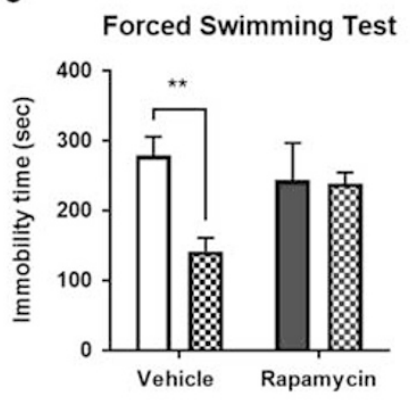

f

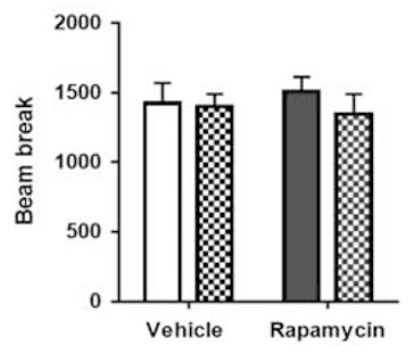

d

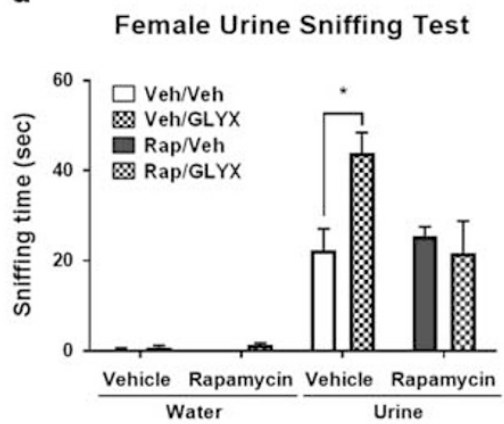

e g

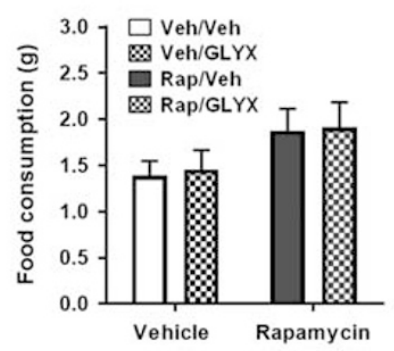

Novelty Suppressed Feeding Test

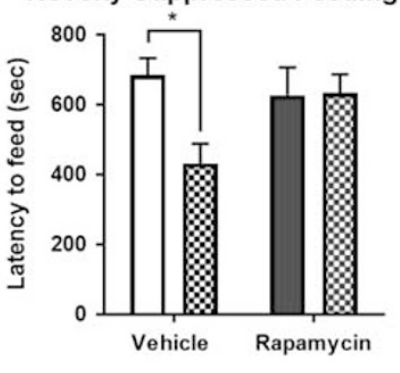

h

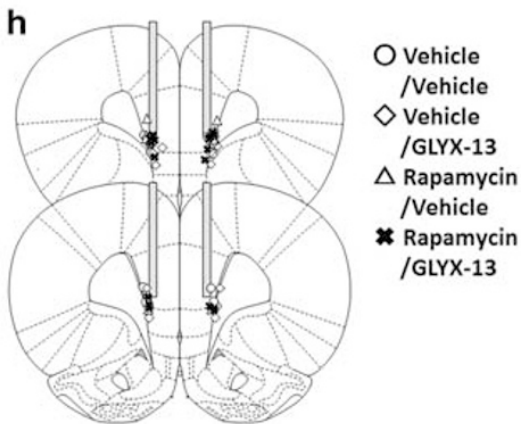

Figure 2 The antidepressant behavioral actions of GLYX-I3 are blocked by infusion of rapamycin into the mPFC. (a) Rats were implanted with bilateral cannula in the mPFC and allowed to recover for approximately 2 weeks. The mTORCI inhibitor rapamycin was infused into the mPFC 30 min prior to administration of vehicle or GLYX-13 (3 mg/kg, i.v.). Twenty-four hr after GLYX-13 administration behavioral studies were initiated and conducted over the next 5 days (c-g). (b) Diagram showing postsynaptic signaling. Significant effects of GLYX-I 3 were observed and were blocked by rapamycin in (c) the FST $(H=12.21, p=0.007)$; (d) the FUST $(H=10.58, p=0.01)$; and (e) the NSFT $(H=8.05, p=0.05)$. No significant effects were seen in ( $f$ locomotor activity $(H=0.69, p=0.88)$ or $(\mathrm{g})$ home cage feeding $(H=6.08, p=0.1 \mathrm{I})$. ${ }^{*} p<0.05$ and $* * * 0.0 \mathrm{I}$ Dunn's post hoc test. The results are shown as mean \pm SEM $n=9$ (veh/veh), and 8-9 (veh/GLYX-13), 4 (Rapa/veh), 9 (Rapa/GLYX-I3). (h) Location of cannulae placements in the mPFC.

significant effects in prelimbic mPFC, similar to the effects of ketamine (Fuchikami et al, 2015).

\section{GLYX-13 Increases Hypocretin- but not 5-HT-Induced EPSCs in mPFC Pyramidal Neurons}

Previous studies demonstrate that ketamine rapidly increases the number and function of spine synapses on layer $\mathrm{V}$ pyramidal neurons in the MPFC (Li et al, 2010; Li et al, 2011). Whole-cell patch recordings of layer $V$ pyramidal cells were conducted to determine the influence of GLYX-13 on 5HT- and hypocretin-induced EPSCs, $24 \mathrm{~h}$ after a single dose. GLYX-13 significantly increased the frequency of hypocretin-induced EPSCs relative to vehicle-treated rats, but had no effect on the frequency of 5-HT-induced EPSCs (Figure 3a and b). This is in contrast to ketamine, which we have previously reported increases both hypocretin- and 5-HT-induced EPSC frequency (Li et al, 2010; Liu et al, 2012, 2013, 2015). GLYX-13 also increased the amplitude of hypocretin-, as well as 5-HT-induced EPSCs (Figure $3 \mathrm{c}$ and $\mathrm{d}$ ).

Cells were passively filled with neurobiotin during recording for subsequent imaging and analysis of dendritic spines. Apical dendrites of filled neurons were scanned using two-photon laser microscopy. GLYX-13 administration significantly increased spine density in layer $\mathrm{V}$ pyramidal neuron dendrites (Figure 4a and b) and frequency distribution analysis suggested a small but significant increase in spine head diameters (Figure $4 \mathrm{c}$ and d). The effects on spine density were confirmed by confocal imaging (Supplementary Figure 3). GLYX-13 administration also increased spine density in basal dendrites of layer $\mathrm{V}$ neurons in $\mathrm{mPFC}$ (Supplementary Figure 4). Similar effects on spine density have been observed with ketamine (Li et al, 2010; Li et al, 2011). Levels of synaptic proteins were also examined $1 \mathrm{hr}$ after a single dose (i.v.) of GLYX-13 or ketamine. Both agents significantly increased levels of GluR1 and synapsin 1, but not PSD95 in synaptosomal fractions of mPFC (Figure 4e-g). 
a

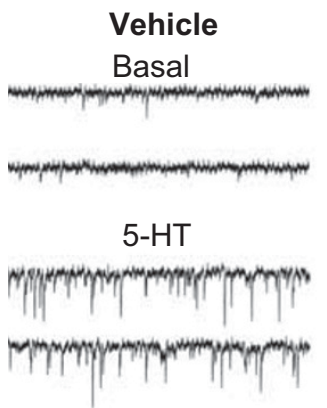

Hypocretin

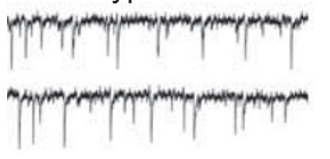

C

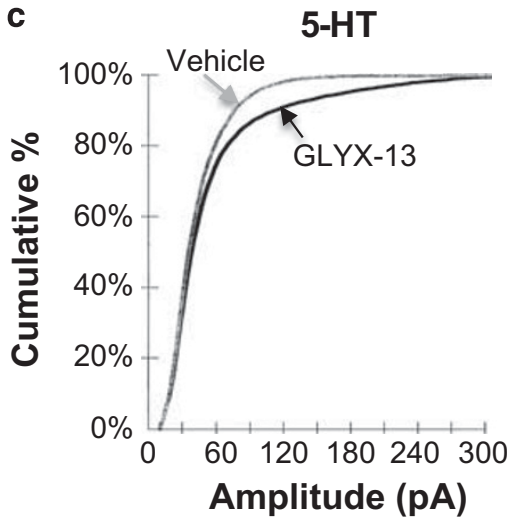

GLYX-13

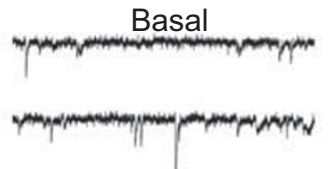

5-HT

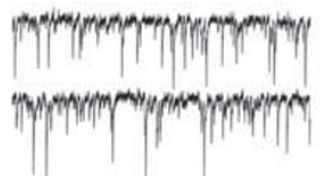

Hypocretin

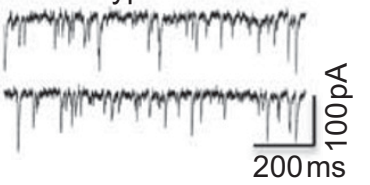

b

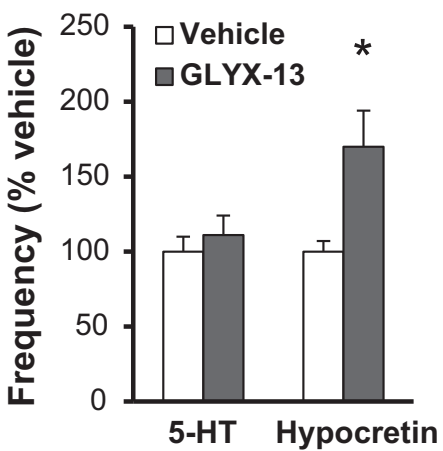

d

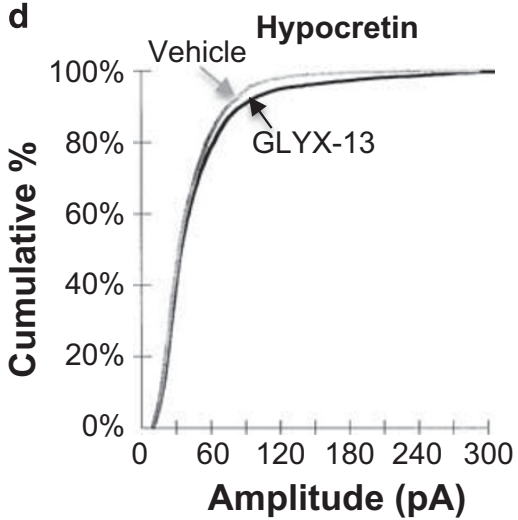

Figure 3 GLYX-13 increases hypocretin- (Hcrt), but not 5-HT-induced EPSCs in layer $V$ pyramidal neurons in mPFC. Rats were administered vehicle or GLYX-I3 (3 mg/kg, i.v.) $24 \mathrm{~h}$ prior to slice preparation, electrophysiological recordings, and neurobiotin filling of patched cells. Layer $V$ pyramidal neurons were patched and 5-HT- or hypocretin-induced EPSCs were determined. (a) Representative traces of EPSC recordings from mPFC of saline vehicle and GLYX-I 3 treatment. (b) Quantification of EPSC frequencies are shown (mean \pm SEM) as percent of control for GLYX-I3, $n=26-27$ cells from 7-8 rats; * $p<0.05$ compared with vehicle control, Student's t-test. (c,d) Cumulative probability distributions showing significantly increased amplitudes (Kolmogorov-Smirnov two-sample test; $p=0.0000, z$ value $=5.25$ for 5 -HT $p=0.0008, z$ value $=1.97$ for hypocretin).

There were no significant effects of GLYX-13 or ketamine on synaptic proteins in the hippocampus or striatum at this time point (Supplementary Figure 5).

\section{Distinct Effects of GLYX-13 and Ketamine on DOI Induced Head Twitch Response and SRTT}

The 5 -HT-induced EPSC response is mediated by $5-\mathrm{HT}_{2 \mathrm{~A}}$ receptors, which are also the binding site of hallucinogenic agents, and could be related to the acute psychotomimetic actions of ketamine or lack thereof with GLYX-13. To examine this possibility, we assessed behavioral response to a $5-\mathrm{HT}_{2 \mathrm{~A} / \mathrm{C}}$ receptor agonist DOI that increases head twitches in mice (Halberstadt and Geyer, 2013; Willins and Meltzer, 1997). Mice were administered ketamine or GLYX-13 and the levels of DOI-induced head twitches were determined $24 \mathrm{~h}$ later. The results demonstrate that ketamine-treated mice displayed significantly increased DOI-induced head twitches over the entire $30 \mathrm{~min}$ test period compared to vehicle controls (Figure $5 \mathrm{a}$ and $\mathrm{b}$ ). In contrast, GLYX-13 had no effect on DOI-induced head twitches at any point in the test period.
We also examined the influence of ketamine and GLYX-13 on behavior in a three-choice SRTT. The SRTT is a highly flexible task used to assess attention and executive function and is modulated by PFC neuronal activity (Bari et al, 2008; Winstanley et al, 2003). During the SRTT rodents must attend to multiple apertures, while waiting for a visual stimulus, which is then reported by a poke into the aperture and rewarded by delivery of a reinforcer. Multiple response errors can be measured, including: premature selection of an aperture, a measure of impulsivity that is mediated by 5$\mathrm{HT}_{2 \mathrm{~A}}$ receptor-cortical-cortical activity in the PFC (Klein et al, 2014; Winstanley et al, 2003), incorrect responses (ie, wrong aperture) and response omissions, which reflect attention deficits that are mediated in part by hypocretininduced thalamocortical glutamate release (Lambe et al, 2005). Task difficulty can be modulated to enhance measures of attention by reducing stimulus duration or to enhance measures of impulsivity by increasing ITI (Figure $5 \mathrm{e}$ and $\mathrm{f}$, respectively).

Mice were trained to respond to approximately $70 \%$ correct over the course of 5 weeks; the final 5-6 sessions before ketamine or GLYX-13 are shown (Figure $5 c$ and d). During 
a
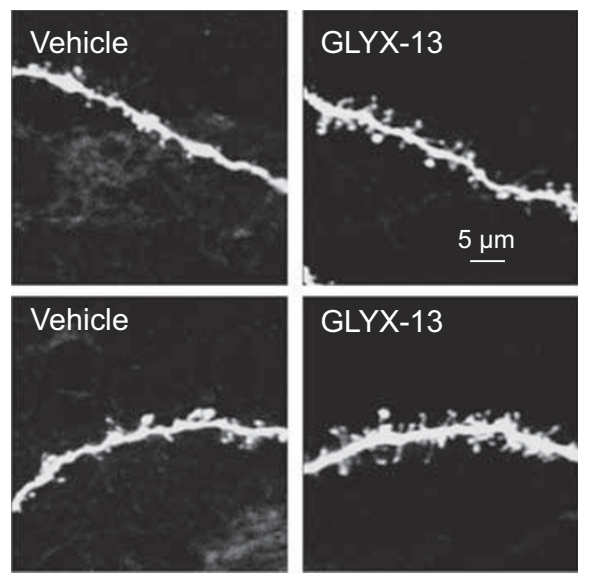

Vehicle $n=9$ cells/51 images

GLYX-13 n=12 cells/64 images b

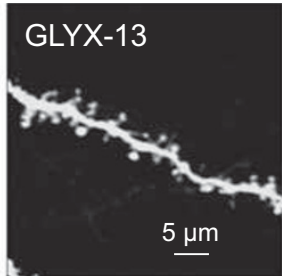

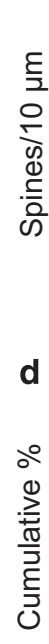

c
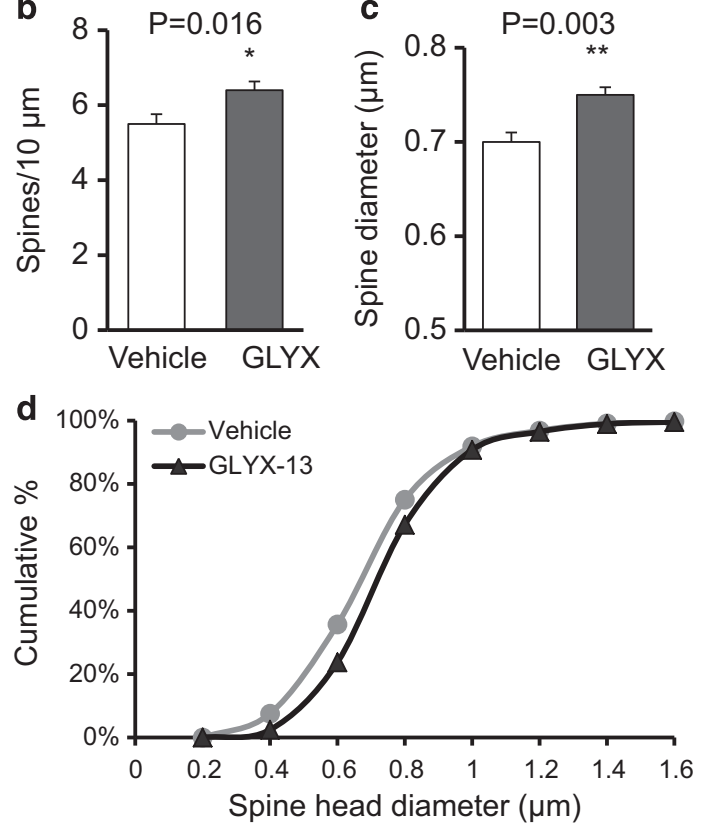

e
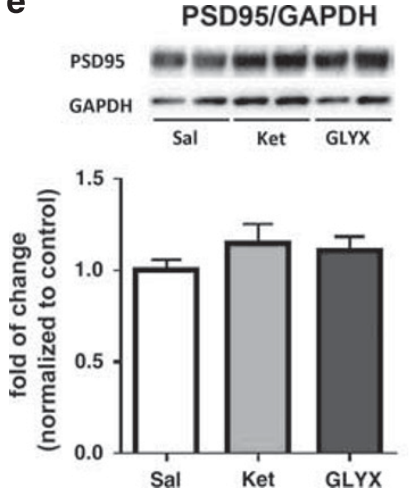

f
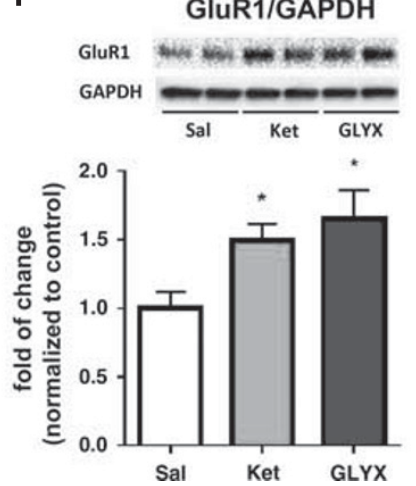

g
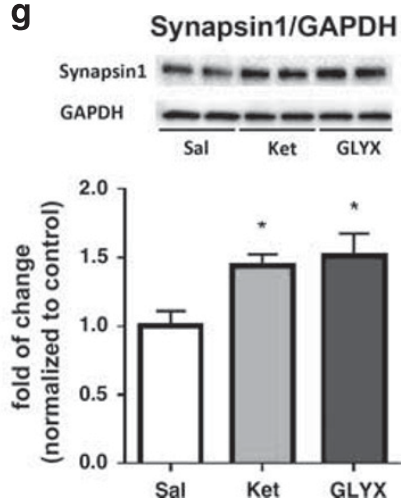

Figure 4 GLYX-13 increases the density of spines in apical dendrites of mPFC layer $\vee$ neurons. Rats were administered vehicle or GLYX-13 (3 mg/kg, i.v.) and pyramidal neurons were filled with neurobiotin during patch recording. (a) Representative two-photon images are shown of high magnification Z-stack projections of the apical dendrite branch segments (scale bar shown in upper right panel). (b) The density of spines and (c) spine head diameter were analyzed using Neurolucida/Autospine (version 10.2). The results in $b$ and $c$ are the mean \pm SEM, $n=9$ cells and $5 \mathrm{I}$ images from 4 rats for vehicle, and $n=12$ cells and 64 images from 4 rats for GLYX-I3; $* p<0.05$ vs control, ${ }^{*} * x<0.01$ vs control (two tailed unpaired Student's t-test). (d) The spine head diameter is also shown in the cumulative fraction curves. (e-g) In a separate experiment, rats were administered vehicle (i.v.), GLYX-I3 (3 mg/kg, i.v.) or ketamine (I 0 mg/kg, i.v.) and PFC dissections were collected I h later. Levels of synaptic proteins were determined by western blot analysis. Levels of GAPDH were determined to control for protein levels and results are the ratio of each synaptic protein divided by GAPDH. Results are the mean \pm SEM, $n=4$ per group. (e) PSD95 was not significantly increased by ketamine or GLYX-13; $F_{2,9}=0.46$, n.s. (f) GluRI was significantly increased by ketamine and $G L Y X-13 ; F_{2,9}=4.95, p<0.04$. (g) Synapsin I was significantly increased by ketamine and GLYX-I 3; $F_{2,9}=4.90, p=0.04$, one-way ANOVA. * $p<0.05$, Fischer's post hoc test.

initial testing when more difficult trials were interspersed with relatively easier trials a trend towards reduced omissions in the ketamine group was apparent (Figure 5e), suggesting enhanced attention. Unlike omissions, incorrect responses were not sensitive to stimulus duration in either group (Figure 5e). Testing impulsivity by presenting trials with longer ITIs increased premature responses in the ketamine group on trials with the longest ITI (Figure 5f). When animals were challenged with a third session that only presented the shortest stimulus duration or longest ITI, ketamine treated animals demonstrated reduced omissions and more premature responses, respectively (Figure $5 \mathrm{~g}$ and $\mathrm{h}$ ). Under the same test conditions, we found that GLYX-13, like ketamine, reduced omissions on trials with a short stimulus duration, indicating enhanced attention that could be related to increased hypocretin responsivity (Figure $5 \mathrm{~g}$ ). However, GLYX-13 did not influence premature responses on long ITI trials that are related to $5-\mathrm{HT}_{2 \mathrm{~A}}$ responses (Figure $5 \mathrm{~h}$ ).

\section{DISCUSSION}

The results demonstrate similarities as well as differences in the synaptic and behavioral actions of GLYX-13 compared with ketamine. GLYX-13 significantly stimulated mTORC1 signaling in the $\mathrm{mPFC}$, including phosphorylated levels of 
mTOR, p70S6K and 4EBP1, as well as the upstream kinases ERK and Akt. In addition, a requirement for mTORC1 was demonstrated as the antidepressant behavioral actions of GLYX-13 were blocked by infusions of the selective inhibitor rapamycin into the $\mathrm{mPFC}$. These results are similar to previous reports demonstrating that ketamine stimulates mTORC1 signaling and that this pathway is required for the behavioral actions of ketamine (Li et al, 2010, 2011; Liu et al, 2013; Dwyer et al, 2012; Yang et al, 2012; Carrier and Kabbaj, 2013; Miller et al, 2014; Paul et al, 2014; Zhou et al, 2014; Chiu et al, 2015; but see Popp et al, 2016). We also found that both GLYX-13 and ketamine stimulated mTORC1 signaling

a

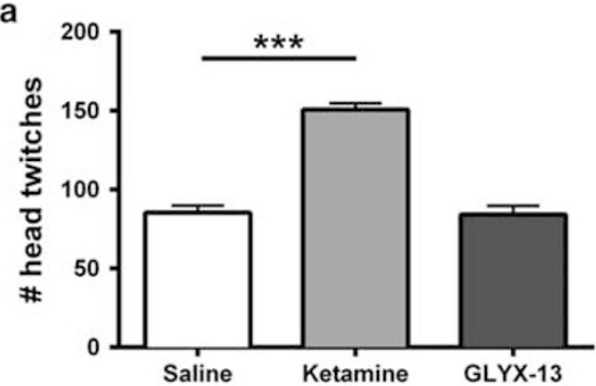

C

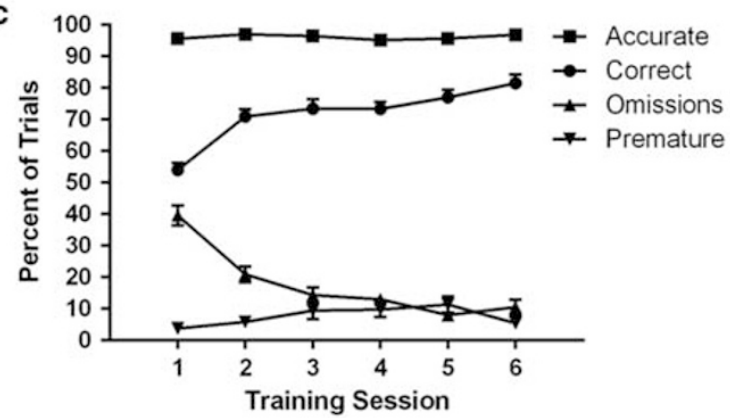

e

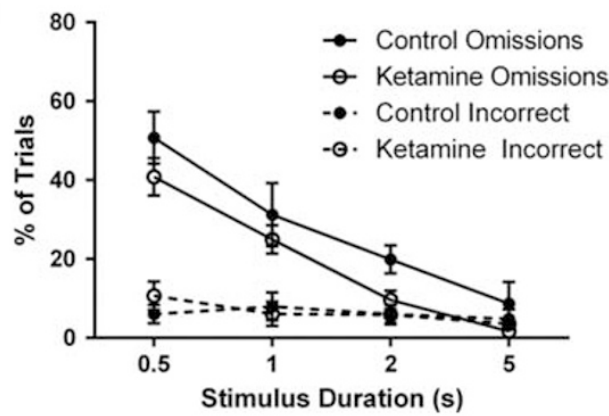

g

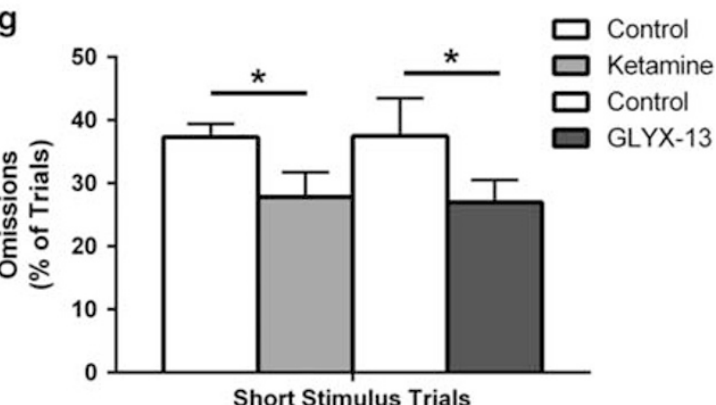

in the hippocampus, consistent with a previous report on GLYX-13 (Lu et al, 2014) and with previous studies of ketamine (Akinfiresoye and Tizabi, 2013; Harraz et al, 2016; Tedesco et al, 2013; Yang et al, 2013; Zhou et al, 2014) but not with the findings of Autry (Autry et al, 2011) in this brain region. The differences in ketamine stimulation of mTORC1 signaling observed in hippocampus as well as PFC (Popp et al, 2016) could be due to multiple variables, notably stress and tissue preparation, that could influence the analysis of dynamic, state dependent phosphorylation of synaptic signaling proteins. b

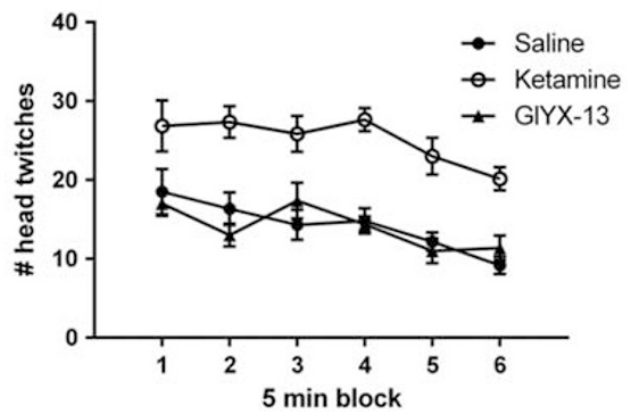

d

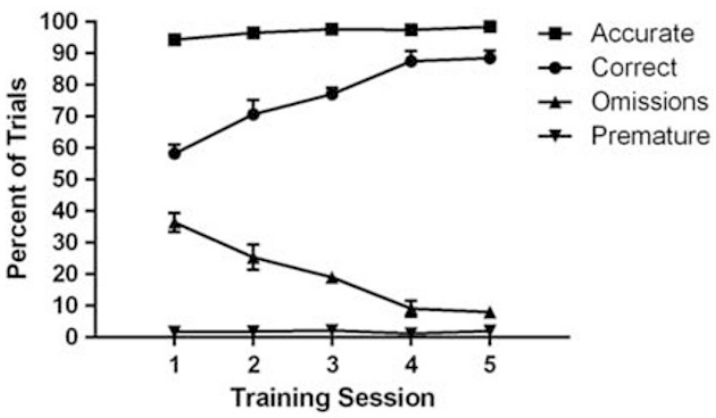

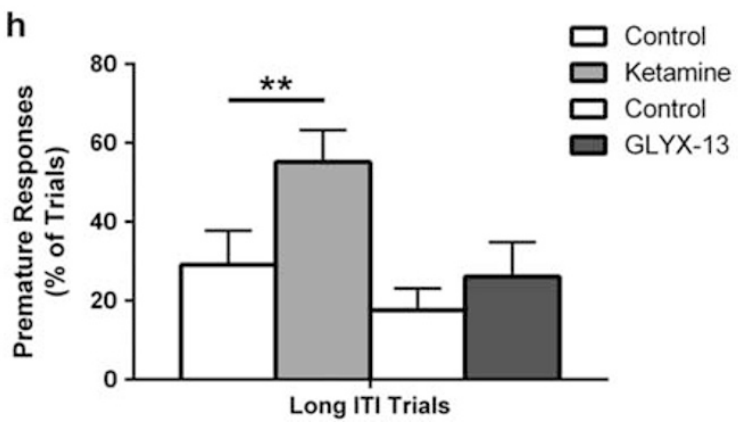


The mTORC1 complex is stimulated by neuronal activity and neurotrophic factor signaling and is required for protein synthesis dependent synaptic plasticity (Duman et al, 2016; Hoeffer and Klann, 2010). In addition, mTORC1 signaling is decreased in rodent chronic stress models and in postmortem PFC of depressed subjects (Jernigan et al, 2011; Ota et al, 2014), suggesting that reductions of this pathway could contribute to the synaptic and behavioral deficits in depression. Stimulation of mTORC1 signaling by ketamine rapidly reverses the reductions in mTORC1 signaling caused by chronic stress, and leads to the rapid reversal of the associated synaptic and behavioral deficits ( $\mathrm{Li}$ et al, 2011). Altogether, these studies and the current findings indicate that stimulation of mTORC1 could contribute to the behavioral as well as synaptic actions of GLYX-13.

Ketamine produces a rapid, transient burst of glutamate in the MPFC and AMPA receptor activation is required for the behavioral actions of ketamine (Moghaddam et al, 1997; Maeng et al, 2008; Li et al, 2010). These effects are also consistent with the rapid induction of the neuronal activity marker c-Fos in the mPFC in response to ketamine (Fuchikami et al, 2015). In the current study, we found that GLYX-13 rapidly increases the expression of c-Fos in the infralimbic mPFC, similar to ketamine (Fuchikami et al, 2015). These results are consistent with the requirement for AMPA receptor activity in the effects of GLYX-13 (Burgdorf et al, 2013), and indicate that both GLYX-13 and ketamine cause rapid neuronal activation in the $\mathrm{MPFC}$, although the mechanisms underlying this increase may differ. The actions of ketamine are thought to occur via increased glutamate and AMPA-induced depolarization of pyramidal neurons (Moghaddam et al, 1997; Homayoun and Moghaddam, 2007); whether GLYX-13 produces a similar increase in glutamate or directly activates pyramidal neurons remains to be determined.

We also found that GLYX-13 significantly increases the frequency of hypocretin-, but not 5-HT-induced EPSCs in layer $\mathrm{V}$ mPFC neurons, a profile that is different from ketamine, which we have shown significantly increases both hypocretin- and 5-HT-induced EPSCs (Li et al, 2010; Liu et al, 2012, 2013, 2015). GLYX-13 increased the amplitudes of 5-HT-induced EPSCs suggesting an increase in efficacy of 5-HT-responsive synapses despite no increase in frequency.
The hypocretin-induced EPSCs are mediated by thalamic inputs to the mPFC (Lambe and Aghajanian, 2003) indicating that GLYX-13 may exert a more robust effect on thalamocortical transmission. The $5-\mathrm{HT}_{2 \mathrm{~A}}$ receptor response, mediated by cortical-cortical projections, has been linked with the psychotomimetic actions of hallucinogens (Aghajanian, 2009). A role for 5- $\mathrm{HT}_{2 \mathrm{~A}}$ receptors in the actions of ketamine is further supported by evidence that the discriminative stimulus effects of ketamine are partially blocked by a selective $5-\mathrm{HT}_{2 \mathrm{~A}}$ antagonist (Yoshizawa et al, 2013).

Analysis of neurobiotin labeled spines from the same neurons undergoing electrophysiological recordings demonstrates that GLYX-13 increased spine density on apical dendrites of layer $\mathrm{V}$ pyramidal neurons. This effect was observed $24 \mathrm{~h}$ following a single dose, indicating that the spine effect outlasts the acute presence of the drug. We also found a modest increase in spine head diameter following GLYX-13 administration. On the basis of the differential effects of GLYX-13 on hypocretin and 5-HT response, it will be interesting in future studies to analyze spines receiving thalamic $v s$ cortical specific inputs, using markers such as vesicular glutamate transporter isoforms that are selectively expressed on these terminals (De Gois et al, 2005).

A significant feature of the behavioral profile of GLYX-13 compared to ketamine is the lack of psychotomimetic effects, which could be related to the 5-HT synaptic differences observed with GLYX-13. The head twitch response (HTR) that is induced by DOI administration and other serotonergic hallucinogens is blocked by $5-\mathrm{HT}_{2 \mathrm{~A}}$ receptor antagonists and is a validated and commonly used behavioral assay for 5$\mathrm{HT}_{2 \mathrm{~A}}$ activation and hallucinogen-like effects (Halberstadt and Geyer, 2013; Willins and Meltzer, 1997). We found that ketamine significantly increased DOI-induced head twitches $24 \mathrm{hr}$ after administration. In contrast, there was no enhancement of DOI-induced head twitches after GLYX-13. The differential effects of ketamine and GLYX-13 were further examined in a SRTT that provides an assessment of attentive and impulsive function. Task difficulty was optimized to allow measures of impulsivity (ie, increased ITI, which increases premature responses) and attention (ie, decreased stimulus duration, which increases omissions) that are mediated by $5-\mathrm{HT}_{2 \mathrm{~A}}$ and hypocretin

Figure 5 Ketamine, but not GLYX-13 increases 5- $\mathrm{HT}_{2}$-induced head twitch and impulsivity. (a,b) Male C57BI/6 mice were administered vehicle (i.v.), GLYX-I3 (3 mg/kg, i.v.) or ketamine (I0 mg/kg, i.v.), and $24 \mathrm{~h}$ later were administered a single dose of the $5-\mathrm{HT}_{2 \mathrm{~A} / \mathrm{C}}$ receptor agonist DOI (5 mg/kg, i.p.). The numbers of head twitches are shown (a) over the total 30 min test period. $n=6$ (sal), 6 (ket), 5 (GLYX-I 3). One-way ANOVA indicated a treatment effect: $F_{2,14}=69.32, p<0.0001$, with ketamine producing more head twitches $t(10)=10.27$, $* * * * p<.0001$. The same data are shown in (b) for 5 min blocks. (c-h) show the results of the serial reaction time task (SRTT). Mice were first trained to respond to a $70 \%$ correct criterion through increasingly short stimulus durations over the course of $\sim 5$ weeks. (c) Final 6 sessions of training ( 5 s stimulus duration, $5 \mathrm{~s}$ ITI). (d) Retraining before GLYX-I 3 administration. Mice were administered vehicle (i.v.) or ketamine ( $10 \mathrm{mg} / \mathrm{kg}$, i.v.) and then, after retraining, vehicle or GLYX-13 (3 mg/kg, i.v.) in a crossover design. Results are shown as mean \pm SEM $n=6$ (ctrl), 7 (ket); 5 (ctrl), 7 (GLYX-13). Data in e-h were analyzed with two-way repeated measures ANOVA, followed by post hoc $t$-tests when indicated. Initial measure validation demonstrated that (e) reducing stimulus duration, $F_{3,33}=35.2 I, p<0.000 \mathrm{I}$ and (f) increasing the intertrial interval $(\mathrm{ITI}), F_{3,33}=18.56, p<0.000 \mathrm{I}$ resulted in increased omissions and impulsivity, respectively. A significant treatment $\times I T I$ interaction, $F_{3,33}=3.4 \mathrm{I}, p<0.05$ supports a ketamine-associated increase in impulsivity at the longest ITI, $t(\mathrm{I} I)=3.47$, $* * x<0.01$. For analysis of attention and impulsivity, respectively, mice were then tested with a session that consisted of random presentation of two trial types; those with (g) short stimulus duration ( $0.5 \mathrm{~s})$ and standard ITI (5 s) in which omissions were measured, or, those with (h) long ITI (I0s) and standard stimulus duration (5 s) in which premature responses were determined. Ketamine treatment was associated with reduced omissions across all trials $F_{1,11}=4.90,{ }^{*} p<0.05$ though this was particularly evident on short stimulus duration trials $t(\mathrm{I} I)=2.74,{ }^{*} p<0.05$. Analysis of impulsivity demonstrated an interaction, $\mathrm{F}_{1,1} \mathrm{I}=5.02, p<0.05$ confirmed by increased premature responses in ketamine treated animals in trials with a long ITI $t(\mathrm{I} I)=2.9 \mathrm{I}$, ${ }^{*} * p<0.0 \mathrm{I}$. In contrast $\mathrm{GLYX}-\mathrm{I} 3$ treatment did not affect impulsivity $F_{I, 10}=0.46, p>0.05$, but was observed to increase attention across trial types $F_{1,10}=5.99, p<0.05$, again most evident in trials with a short stimulus duration $t(10)=2.45$, $* p<0.05$. 
responses, respectively, to be determined (Lambe et al, 2005). These results demonstrate that ketamine, but not GLYX-13 increases the number of premature responses (ie, impulsivity) when the ITI is long. Moreover, both ketamine and GLYX-13 reduce omissions when the stimulus duration is short, indicating an increase in attention. These findings, along with the DOI-induced head twitch response, are consistent with the electrophysiology showing differences between ketamine and GLYX-13 in 5-HT- and hypocretininduced responses. This adds to previous work showing different behavioral profiles, including substance abuse related (conditioned place preference), sensori-motor gating deficits (prepulse inhibition; Burgdorf et al, 2013), and declarative memory impairment induced by ketamine but not GLYX-13 (Rajagopal et al, 2016).

The different synaptic and behavioral effects of GLYX-13 and ketamine likely relate to different primary sites of action and receptor selectivity. GLYX-13 is an NMDA modulator with glycine site partial agonist properties and ketamine is an activity dependent nonselective NMDA open channel blocker (Moskal et al, 2016; Traynelis et al, 2010). Bathapplied GLYX-13 as well as another glycine partial agonist, D-cycloserine enhances long-term potentiation (LTP) in hippocampal Schaffer collateral-CA1 synapses (Zhang et al, 2008), and in vivo administration of GLYX-13 enhances subsequent hippocampal slice LTP (Burgdorf et al, 2015b), suggesting that glycine site partial agonist properties underlie the actions of GLYX-13 on synaptic plasticity in the hippocampus. GLYX-13 administration also produces a long-lasting increase in NMDA current conductance (Burgdorf et al, 2015b), and the observations that GluN2B selective antagonists block the effects of GLYX-13 on NMDA currents and LTP indicate a role of this receptor subtype in the actions of GLYX-13. These effects of GLYX-13 on plasticity-related processes could be related to the cognitive enhancing and antidepressant actions of GLYX-13, as well as the ability of GLYX-13 to block the effects of ketamine in a declarative memory task (Rajagopal et al, 2016). Further studies of the binding characteristics and subunit selectivity in different types of neurons in the PFC and other brain regions are required to fully elucidate the actions of GLYX-13 and to inform the development of novel glycine site agents.

Our results highlight key similarities but also differences in the signaling, electrophysiology, and behavioral actions of GLYX-13 and ketamine. The lack of psychotomimetic side effects of GLYX-13 compared with ketamine may be related to different actions on $5-\mathrm{HT}_{2 \mathrm{~A}}$ receptor-sensitive cortical circuitry, whereas regulation of hypocretin-sensitive circuitry could be related to the therapeutic benefits of both rapid acting antidepressants. There is evidence that the hypocretin/ orexin system is involved in stress and depression (Liu and Aghajanian, 2008; Li et al, 2011), and orexin signaling is being targeted for development of novel therapeutic agents (Nollet and Leman, 2013). A role for a hypocretin-sensitive thalamocortical pathway in antidepressant responses could be related to the actions of this circuit on arousal and flexibility of cortical systems. Further studies are required to determine the precise cellular mechanisms underlying the actions of GLYX-13, including the relative importance of direct $v s$ indirect effects on glutamate transmission in the PFC.

\section{FUNDING AND DISCLOSURE}

This work is supported by NIMH R37MH45481 (RSD), NIMH R01MH93897 (RSD), a research grant from Naurex, the State of Connecticut, and Yale University. R.S. Duman has consulted and/or received research support from Naurex, Lilly, Forest, Johnson \& Johnson, Taisho, and Sunovion; J.R. Moskal is the founder and has stock in Naurex, Inc; he also receives financial compensation as a consultant. J.S. Burgdorf is a consultant for Naurex, Inc., and has received financial compensation and stock. The remaining authors declare no conflict of interest.

\section{ACKNOWLEDGMENTS}

We thank Dr Stephanie Groman and Ms. Carol Gianessi for assistance with the serial reaction time task.

\section{REFERENCES}

Abdallah CG, Sanacora G, Duman RS, Krystal JH (2015). Ketamine and rapid-acting antidepressants: a window into a new neurobiology for mood disorder therapeutics. Annu Rev Med 66: 509-523.

Aghajanian G (2009). Modeling 'psychosis' in vitro by inducing disordered neuronal network activity in cortical brain slices. Psychopharmacology 206: 575-585.

Akinfiresoye L, Tizabi Y (2013). Antidepressant effects of AMPA and ketamine combination: role of hippocampal BDNF, synapsin, and mTOR. Psychopharmacology (Berl) 230: 291-298.

Autry AE, Adachi M, Nosyreva E, Na ES, Los MF, Cheng PF et al (2011). NMDA receptor blockade at rest triggers rapid behavioural anatidepressant responses. Nature 475: 91-95.

Bari A, Dalley JW, Robbins TW (2008). The application of the 5choice serial reaction time task for the assessment of visual attentional processes and impulse control in rats. Nat Protoc 3: 759-767.

Berman RM, Cappiello A, Anand A, Oren DA, Heninger GR, Charney DS et al (2000). Antidepressant effects of ketamine in depressed patients. Biol Psychiatry 47: 351-354.

Burch R, Amin Khan M, Houck D, Yu W, Gaines C, Burgdorf J et al (2016). NMDA receptor glycine site modulators as therapeutics for depression: rapastinel has antidepressant activity without causing psychotomimetic side effects. Curr Neuropharmacol (e-pub ahead of print February 2016; doi:10.2174/1570159X14666160202121319).

Burgdorf J, Kroes R, Zhang X, Gross A, Schmidt M, Weiss C et al (2015b). Rapastinel (GLYX-13) has therapeutic potential for the treatment of post-traumatic stress disorder: Characterization of a NMDA receptor-mediated metaplasticity process in the medial prefrontal cortex of rats. Behav Br Res 294: 177-185.

Burgdorf J, Zhang X, Nicholson K, Balster R, Leander J, Stanton P et al (2013). GLYX-13, a NMDA receptor glycine-site functional partial agonist, induces antidepressant-like effects without ketamine-like side effects. Neuropsychopharmacology 38: 729-742.

Burgdorf J, Zhang X, Weiss C, Gross A, Boikess S, Kroes R et al (2015a). The long-lasting antidepressant effects of rapastinel (GLYX-13) are associated with a metaplasticity process in the medial prefrontal cortex and hippocampus. Neuroscience 308: 202-211.

Carrier N, Kabbaj M (2013). Sex differences in the antidepressantlike effects of ketamine. Neuropharmacology 70: 27-34.

Chiu CT, Scheuing L, Liu G, Liao HM, Linares GR, Lin D et al (2015). The mood stabilizer lithium potentiates the antidepressant-like effects and ameliorates oxidative stress induced by acute 
ketamine in a mouse model of stress. Int J Neuropsychopharmacol 18 (doi:10.1093/ijnp/pyu1102).

De Gois S, Schafer MK, Defamie N, Chen C, Ricci A, Weihe E et al (2005). Homeostatic scaling of vesicular glutamate and GABA transporter expression in rat neocortical circuits. J Neurosci 25: 7121-7133.

Duman R, Aghajanian A, Sanacora G, Krystal J (2016). A synaptic hypothesis of depression: new insights from studies of stress systems and rapid-acting antidepressant. Nat Med 22: 238-249.

Duman R, Aghajanian G (2012). Synaptic dysfunction in depression: novel therapeutic targets. Science 338: 68-72.

Dwyer J, Lepack AE, Duman RS (2012). mTOR activation is required for the antidepressants effects of mGluR2/3 blockade. Int J Neuropsychopharmacol 15: 429-434.

Fuchikami M, Thomas A, Liu R, Wohleb ES, Land BB, DiLeone RJ et al (2015). Optogenetic stimulation of infralimbic PFC reproduces ketamine's rapid and sustained antidepressant actions. Proc Natl Acad Sci USA 112: 8106-8111.

Halberstadt A, Geyer M (2013). Characterization of the head-twitch response induced by hallucinogens in mice: detection of the behavior based on the dynamics of head movement. Psychopharmacology 227: 727-739.

Harraz M, Tyagi R, Cortés P, Snyder S (2016). Antidepressant action of ketamine via mTOR is mediated by inhibition of nitrergic Rheb degradation. Mol Psychiatry 21: 313-319.

Hoeffer CA, Klann E (2010). mTOR signaling: at the crossroads of plasticity, memory and disease. Trends Neurosci 33: 67-75.

Homayoun H, Moghaddam B (2007). NMDA receptor hypofunction produces opposite effects on prefrontal cortex interneurons and pyramidal neurons. J Neurosci 27: 11496-11500.

Jernigan CS, Goswami DB, Austin MC, Iyo AH, Chandran A, Stockmeier CA et al (2011). The mTOR signaling pathway in the prefrontal cortex is compromised in major depressive disorder. Prog Neuropsychopharmacol Biol Psychiatry 35: 1774-1779.

Klein AB, Ultved L, Adamsen D, Santini MA, Tobena A, Fernandez-Teruel A et al (2014). 5-HT(2A) and mGlu2 receptor binding levels are related to differences in impulsive behavior in the Roman Low- (RLA) and High- (RHA) avoidance rat strains. Neuroscience 263: 36-45.

Lambe E, Aghajanian GK (2003). Hypocretin (orexin) induces calciuim transients in single spines postsynaptic to identified thalamocortical boutons in prefrontal slice. Neuron 40: 139-150.

Lambe EK, Olausson P, Horst NK, Taylor JR, Aghajanian GK (2005). Hypocretin and nicotine excite the same thalamocortical synapses in prefrontal cortex: correlation with improved attention in rat. J Neurosci 25: 5225-5229.

Li N, Lee B, Liu RJ, Banasr M, Dwyer JM, Iwata M et al (2010). mTOR-dependent synapse formation underlies the rapid antidepressant effects of NMDA antagonists. Science 329: 959-964.

Li N, Liu RJ, Dwyer JM, Banasr M, Lee B, Son H et al (2011). Glutamate $\mathrm{N}$-methyl-D-aspartate receptor antagonists rapidly reverse behavioral and synaptic deficits caused by chronic stress exposure. Biol Psychiatry 69: 754-761.

Liu R-L, Ota KT, Dutheil S, Duman RS, Aghajanian G (2015). Ketamine strengthens CRF-activated amygdalar synaptic inputs to basilar dendrites in $\mathrm{mPFC}$ layer $\mathrm{V}$ pyramidal cells in the prelimbic but not infralimbic subregion, a key suppressor of stress responses. Neuropsychopharmacol 40: 2066-2075.

Liu RJ, Aghajanian GK (2008). Stress blunts serotonin- and hypocretin-evoked EPSCs in prefrontal cortex: role of corticosterone-mediated apical dendritic atrophy. Proc Natl Acad Sci USA 105: 359-364.

Liu RJ, Fuchikami M, Dwyer JM, Lepack AE, Duman RS, Aghajanian GK (2013). GSK-3 inhibition potentiates the synaptogenic and antidepressant-like effects of subthreshold doses of ketamine. Neuropsychopharmacology 38: 2268-2277.

Liu RJ, Lee FS, Li XY, Bambico F, Duman RS, Aghajanian GK (2012). Brain-derived neurotrophic factor Val66Met allele impairs basal and ketamine-stimulated synaptogenesis in prefrontal cortex. Biol Psychiatry 71: 996-1005.

Lu Y, Wang C, Xue Z, Li C, Zhang J, Zhao X et al (2014). $\mathrm{PI} 3 \mathrm{~K} / \mathrm{AKT} / \mathrm{mTOR}$ signaling-mediated neuropeptide VGF in the hippocampus of mice is involved in the rapid onset antidepressant-like effects of GLYX-13. Int J Neuropsychopharmacol 18: pii: pyu110. doi:10.1093/ijnp/pyu110.

Maeng S, Zarate CA Jr., Du J, Schloesser RJ, McCammon J, Chen G et al (2008). Cellular mechanisms underlying the antidepressant effects of ketamine: role of alpha-amino-3-hydroxy-5-methylisoxazole-4-propionic acid receptors. Biol Psychiatry 63: 349-352.

Malkesman O, Scattoni M, Paredes D, Tragon T, Pearson B, Shaltiel $\mathrm{G}$ et al (2010). The female urine sniffing test: a novel approach for assessing reward-seeking behavior in rodents. Biol Psychiatry 67: 864-871.

Miller OH, Yang L, Wang CC, Hargroder EA, Zhang Y, Delpire E et al (2014). GluN2B-containing NMDA receptors regulate depression-like behavior and are critical for the rapid antidepressant actions of ketamine. Elife 3: e03581.

Moghaddam B, Adams B, Verma A, Daly D (1997). Activation of glutamatergic neurotransmission by ketamine: a novel step in the pathway from NMDA receptor blockade to dopaminergic and cognitive disruptions associated with the prefrontal cortex. J Neurosci 17: 2921-2927.

Moskal J, Burgdorf J, Stanton P, Kroes R, Disterhoft J, Burch R et al (2016). The development of Rapastinel (formerly GLYX-13); a rapid acting and long lasting antidepressant. Curr Neuropharmacol (e-pub ahead of print 21 March 2016).

Moskal JR, Kuo AG, Weiss C, Wood PL, O'Connor Hanson A, Kelso $S$ et al (2005). GLYX-13: a monoclonal antibody-derived peptide that acts as an N-methyl-D-aspartate receptor modulator. Neuropharmacology 49: 1077-1087.

Nollet M, Leman S (2013). Role of orexin in the pathophysiology of depression: potential for pharmacological intervention. CNS Drugs 27: 411-422.

Ota K, Liu RJ, Voleti B, Maldonado-Aviles JG, Duric V, Iwata M et al (2014). REDD1 is essential for stress-induced synaptic loss and depressive behavior. Nat Med 20: 531-535.

Paul RK, Singh NS, Khadeer M, Moaddel R, Sanghvi M, Green CE et al (2014). (R,S)-Ketamine metabolites (R,S)-norketamine and (2S,6S)-hydroxynorketamine increase the mammalian target of rapamycin function. Anesthesiology 121: 149-159.

Popp S, Behl B, Joshi J (2016). In search of the mechanisms of ketamine's antidepressant effects: How robust is the evidence behind the mTor activation hypothesis. F1000 Res 5: 634.

Rajagopal L, Burgdorf JS, Moskal JR, Meltzer HY (2016). GLYX-13 (rapastinel) ameliorates subchronic phencyclidine- and ketamineinduced declarative memory deficits in mice. Behav Brain Res 299: 105-110.

Rodriguez A, Ehlenberger DB, Dickstein DL, Hof PR, Wearne S (2008). Automated three-dimensional detection and shape classification of dendritic spines from fluorescence microscopy images. PLoS ONE 3: e1997.

Scott D, Taylor JR (2014). Chronic nicotine attenuates phencyclidine-induced impulsivity in a mouse serial reaction time task. Behav Brain Res 259: 164-173.

Tedesco V, Ravagnani C, Bertoglio D, Chiamulera C (2013). Acute ketamine-induced neuroplasticity: ribosomal protein S6 phosphorylation expression in drug addiction-related rat brain areas. Neuroreport 24: 388-393.

Traynelis SF, Wollmuth LP, McBain CJ, Menniti FS, Vance KM, Ogden KK et al (2010). Glutamate receptor ion channels: structure, regulation, and function. Pharmacol Rev 62: 405-496.

Trivedi M, Rush AJ, Wisniewski SR, Nierenberg AA, Warden D, Ritz L et al (2006). Evaluation of outcomes with citalopram for depression using measurement-based care in $\mathrm{STAR}^{\star} \mathrm{D}$ : implications for clinical practice. Am J Psychiatry 163: 28-40. 
Warner-Schmidt JL, Duman RS (2007). VEGF is an essential mediator of the neurogenic and behavioral actions of antidepressants. Proc Natl Acad Sci USA 104: 4647-4652.

Willins D, Meltzer H (1997). Direct injection of 5-HT2A receptor agonists into the medial prefrontal cortex produces a head-twitch response in rats. J Pharm Exp Ther 282: 699-706.

Winstanley CA, Chudasama Y, Dalley JW, Theobald DE, Glennon JC, Robbins TW (2003). Intra-prefrontal 8-OH-DPAT and M100907 improve visuospatial attention and decrease impulsivity on the five-choice serial reaction time task in rats. Psychopharmacology (Berl) 167: 304-314.

Yang C, Hu YM, Zhou ZQ, Zhang GF, Yang JJ (2013). Acute administration of ketamine in rats increases hippocampal BDNF andmTOR levels during forced swimming test. Ups J Med Sci 118: 3-8.

Yang C, Li WY, Yu HY, Gao ZQ, Liu XL, Zhou ZQ et al (2012). Tramadol pretreatment enhances ketamine-induced antidepressant effects and increases mammalian target of rapamycin in rat hippocampus and prefrontal cortex. J Biomed Biotechnol 2012: 175619.

Yoshizawa K, Mori T, Ueno T, Nishiwaki M, Shibasaki M, Shimizu $\mathrm{N}$ et al (2013). Involvement of serotonin receptor mechanisms in the discriminative stimulus effects of ketamine in rats. J Pharmacol Sci 121: 237-241.

Zhang XL, Sullivan JA, Moskal JR, Stanton PK (2008). A NMDA receptor glycine site partial agonist, GLYX-13, simultaneously enhances LTP and reduces LTD at Schaffer collateral-CA1 synapses in hippocampus. Neuropharmacology 55: $1238-1250$.

Zhou W, Wang N, Yang C, Li XM, Zhou ZQ, Yang JJ (2014). Ketamine-induced antidepressant effects are associated with AMPA receptors-mediated upregulation of mTOR and BDNF in rat hippocampus and prefrontal cortex. Eur Psychiatry 29: 419-423.

Supplementary Information accompanies the paper on the Neuropsychopharmacology website (http://www.nature.com/npp) 